\title{
Gender Differences in the Link between Family Scholarly Culture and Parental Educational Aspirations ${ }^{1}$
}

\author{
Dana Hamplová ${ }^{2}$ - Petra Raudenská ${ }^{3}$ \\ Institute of Sociology of the Czech Academy of Sciences, Prague
}

\begin{abstract}
Gender Differences in the Link between Family Scholarly Culture and Parental Educational Aspirations. This study investigated family scholarly culture's effects on parental educational aspirations, with special attention paid to gender differences based on the ideas of stratified parenting and a sociocultural approach to parenting. Two-level structural modeling was applied to nationally representative Czech Household Panel Survey data from 2015 - 2016. Overall, our analysis did not find an independent effect from scholarly culture on parental educational aspirations after controlling for several socioeconomic characteristics. However, we demonstrated that scholarly culture stratifies gender differences in parental educational aspirations. Families with weaker scholarly culture hold higher aspirations for daughters than for sons, while families with stronger scholarly culture have similar aspirations for both boys and girls. Thus, we observed that scholarly culture stratifies gender differentiation of educational aspirations for boys and girls. Sociológia 2021, Vol. 53 (No. 5: 435-462)

https://doi.org/10.31577/sociologia.2021.53.5.16
\end{abstract}

Key words: Scholarly culture; gender; parental educational aspirations; education; structural modeling

\section{Introduction}

Given its role in academic and occupational success, parental educational aspirations have attracted considerable interest from both academics and policymakers (Agger et al. 2018; Lazarides et al. 2016; Matějů - Smith 2009). Higher-aspiring parents are more likely to invest in their children's education and extracurricular activities, as well as books and other educational resources, while helping their children with their homework, and/or conveying the value of education to them (Kirk et al. 2011; Sosu 2014; Spera 2006). Existing studies have demonstrated that parental educational aspirations are tied to the family's socioeconomic status and demographic characteristics, family type, or the child's academic performance (Sosu 2014; Spera et al. 2009). Nevertheless, little is known about whether and how parental educational aspirations are linked with non-economic characteristics, such as family (scholarly) culture. However, these characteristics increasingly have been capturing attention in stratification research, as they may have higher predictive power for status

\footnotetext{
1 This work was supported by the Czech Science Foundation 'Transformation of gender gaps in the Czech educational system and the labor market: Dynamics, causes and consequences' (Grant No. 19-15303S)

2 Address: Prof. Dana Hamplová, Ph.D., Institute of Sociology, Czech Academy of Sciences, Jilská 1, 11000 Prague 1, Czech Republic. E-mail: dana.hamplova@soc.cas.cz

3 Address: PhDr. Petra Raudenská, Ph.D., Institute of Sociology, Czech Academy of Sciences, Jilská 1, 11000 Prague 1, Czech Republic. E-mail: petra.raudenska@soc.cas.cz
} 
achievement than financial and other socioeconomic resources (De Graaf et al. 2000; Jæger - Holm 2007).

This paper contributes to the existing literature in three ways. First, it focuses on a specific dimension of cultural capital - scholarly culture - by examining the link between scholarly culture and parental educational aspirations. Although various papers have examined the link between scholarly culture and educational attainment (Blaabæk 2020; De Graaf et al. 2000; Evans et al. 2015), or between aspirations and other dimensions of cultural capital (Gao - Ng 2017), the link between scholarly culture and parental educational aspirations generally has been neglected. We believe that it is important to focus on a specific form of cultural capital, as its different forms seem to affect aspirations differently (Gao - Ng 2017; Van de Werfhorst - Hofstede 2007).

Second, this paper distinguishes between various dimensions of scholarly culture. There is systematic cross-national evidence that family library size (the most common measure of scholarly culture) is linked positively to more schooling, better academic performance, and higher educational achievement (Evans et al. 2014; Evans et al. 2010; Park 2008). However, this measure confounds several dimensions of scholarly culture: cognitive or vocabulary enhancement; membership in elite culture; and parental human capital (Evans et al. 2014; Evans et al. 2015). Thus, library size typically is used as a measure of both embodied and objectified culture in Bourdieu's sense (1984). This paper's novelty is that we directly distinguish between the objectified dimension of scholarly culture (number of books) and the embodied dimension (reading culture).

This paper's third fundamental contribution concerns gender differences. We asked whether scholarly culture level affects the gender gap in parental educational aspirations. Several studies have suggested that parents have different aspirations for boys compared with girls (DiPrete - Buchmann 2013; Schoon et al. 2007), or that intergenerational transmission (heritability) of educational attainment is not the same for both sexes (Branigan et al. 2013). By adopting a sociocultural approach to parenting (Yamamoto - Holloway 2010), we posited that scholarly culture attributes differently to skills valued in boys and girls. Moreover, scholarly culture's role in the formation of educational aspirations also might differ for fathers and mothers. Indeed, some empirical evidence indicates that the mother's and father's cultural capital affects girls and boys differently (Mullan 2010; Wollscheid 2013). Thus, to fully understand the link between aspirations, gender, and scholarly culture, we investigated parent-child dyads to distinguish between various gender constellations.

The article is organized as follows. We start by discussing the key theoretical terms. First, we introduce the concept of parental educational 
aspirations, then discuss the concept of scholarly culture and how it relates to the broader theory of cultural capital. We are aware that some researchers view aspirations as part of cultural capital (Tan 2017a; Tan 2017b). However, in this article, we built on the research tradition that treats aspirations and cultural capital as two distinct concepts (Holmes et al. 2018; Moote et al. 2020; Strand - Winston 2008; Van de Werfhorst - Hofstede 2007). First, while some dimensions of cultural capital likely are linked to educational aspirations (e.g. cultural value of college, see Gao - Ng 2017), the link is much less clear for some other dimensions (Van de Werfhorst - Hofstede 2007). Second, cultural resources are only one of many factors affecting aspirations. In the rational theory framework, aspirations are a product of rational calculus, and the decisive factors are direct, indirect, and opportunity costs and benefits (Goldthorpe 2007; Zimmermann 2020). Third, there are also empirical reasons to distinguish between aspirations and cultural capital. Studies have demonstrated that the desire for upward social status mobility among disadvantaged, minority, and immigrant groups often leads to very high aspirations despite low levels of other types of capital (DeWitt et al. 2011; Dollmann - Weißmann 2020; Salikutluk 2016; Strand - Winston 2008; Taylor - Krahn 2005). Finally, the idea that aspirations are not just an expression of parental cultural capital is supported by the fact that some dimensions of cultural capital (e.g., parental involvement in highbrow culture) are not linked directly to educational ambitions (Van de Werfhorst - Hofstede 2007).

After introducing the concepts of parental aspirations and scholarly culture, we discuss gender differences. Our approach is informed by the sociocultural approach (Yamamoto - Holloway 2010) and the stratified parenting perspective (Baier 2019; Baier - Lang 2019). Finally, the hypotheses are tested using Czech Household Panel Survey data from 2015 and 2016.

\section{Theoretical background}

\section{Parental educational aspirations}

Parental aspirations can be understood as a belief system that organizes, communicates, and directs parents' behaviors toward their children (Spera et al. 2009). Although the relationship between parental educational aspirations and student outcomes has been well-demonstrated (Agger et al. 2018; Fan Williams 2010; Jeynes 2007), the question of what factors predict parental educational aspirations has received limited attention and remains rather unclear (Vryonides - Gouvias 2012). Most studies focus on factors such as parents' socioeconomic status (SES) and demographic characteristics, family type, or the child's academic performance (Sosu 2014; Spera et al. 2009).

Past research has demonstrated that parents with higher SES backgrounds (in terms of job status, education, or income) tend to hold higher educational 
aspirations for their children compared with those from lower SES backgrounds (Esping-Andersen 2004; Schoon et al. 2007; Spera et al. 2009). These higher SES parents have more resources that can be redirected into more demanding educational pathways for their children. They also have educationally relevant social networks and experience, giving them the confidence to set higher goals or enhance their ability to help their children with schoolwork (Sosu 2014). Furthermore, downward mobility avoidance and effectively maintained inequality theories imply that upper-class parents are also driven by a desire to maintain their families' social standing and protect their children from downward mobility (Bernardi - Gil-Hernández 2020; Lucas 2001).

In addition to parental resources, several child-level characteristics have been found to influence parental educational aspirations, e.g., children's academic achievement, gender, emotional and behavioral dispositions, and birth order. Parents tend to hold higher educational aspirations for highachieving children and lower aspirations for those not doing well at school (Kirk et al. 2011). Price (2008) proposed that first-born children receive greater psychological resource endowments because they have only-child status during the early years of life, compared with subsequent children, who must share parental resources. In line with this argument, Sosu (2014) found that parents also hold higher aspirations for first-born children than other children in the birth order. Like birth order, family size equally can influence parental educational aspirations through resource dilution. Parents with smaller family sizes are likely to have more financial resources, and as a result, set higher aspirations.

However, although "hard" socioeconomic factors are important, some other family/individual characteristics might be drivers of parental educational aspirations as well. Furthermore, in some aspects, non-economic factors, such as cultural capital or scholarly culture, might be even more important in predicting parental aspirations.

\section{Cultural capital vs. scholarly culture}

The current study aims to examine the link between family scholarly culture and parental educational aspirations. Scholarly culture might be viewed as a particular expression or dimension of a broader concept of cultural capital.

Pierre Bourdieu (1984) and Paul DiMaggio's (1982) theories on cultural capital are among the most influential explanations of why cultural capital matters. While DiMaggio (1982) focused on cultural capital's role as a means of social mobility, Bourdieu (1984) emphasized its importance in the reproduction of existing hierarchies. He argued that cultural capital (in its various expressions) is a resource that families use to promote their own position within the social hierarchy. Considering that families in higher 
socioeconomic positions possess more cultural capital, and that cultural capital is passed from parents to children, it contributes to social inequality by reproducing existing hierarchies. Following upon Bourdieu's theory, Jæger and Breen (2016) develop a formal model of the pathways through which cultural capital acts to enhance children's educational and socioeconomic success. Indeed, family cultural capital's impact on a child's school trajectory and education attained has been demonstrated extensively (Breinholt - Jæger 2020; De Graaf et al. 2000; DiMaggio 1982; Evans et al. 2015; Van de Werfhorst Hofstede 2007).

Typically, cultural capital refers to familiarity with the dominant culture, attitudes, values, preferences, tastes, linguistic competencies, and mannerisms, as well as ownership and consumption of cultural/educational goods and involvement in cultural products (Jæger - Breen 2016; Van de Werfhorst 2010; Vryonides 2007). In this paper, we focused on a specific dimension of cultural capital - scholarly culture - which is a distinct concept and has a narrower meaning than cultural capital. It refers specifically to the ownership and use of one type of cultural goods: books (Evans et al. 2010; Kelley - Evans 2000). We believe that this dimension of cultural capital is particularly important for educational success, expectations, and ambition, as it is linked directly to academic processes.

Previous empirical studies have demonstrated that scholarly culture (usually measured by the number of books in the parental home) is linked closely to children's educational achievement. For example, children growing up in families with larger libraries perform better on reading tests (Park 2008). A recent study by Evans et al. (2015) demonstrated that children who grew up in otherwise similar families with over 500 books at home spent three more years in school on average. Past studies also indicate that family library size reliably predicts achievement in school across different social and political circumstances (Evans et al. 2010).

Two mechanisms are invoked to explain why library size matters (Evans et al. 2014; Evans et al. 2010). Some authors argue that library size signals elite membership and helps protect privileges of higher social classes. This argument reflects the traditional view of cultural capital, according to which the education system is biased and attributes better qualities to students and families with large libraries (Jæger - Breen 2016). However, others maintain that larger libraries promote cognitive enhancement, a larger vocabulary, and cognitive skills (Evans et al. 2014; Schmitt et al. 2011). The difference between status enhancement and cognitive enhancement also is echoed in DiMaggio's distinctions between cultural capital as a means to indicate status group membership and cultural capital and as a means to form shared cognitive structure (DiMaggio 1982; DiMaggio 1997). 
Thus, existing research tends to view library size as a measure of both objectified and embodied scholarly culture (Bourdieu 1984). In this paper, we distinguish between these two expressions of scholarly culture: the size of the family library (with number of books at home indicating objectified scholarly culture) and reading culture (the extent to which books are esteemed, read, and enjoyed as embodied scholarly culture). Objectified scholarly culture (library size) may signal elite/group membership, which may be particularly true if we are interested in explaining parental educational aspirations for offspring. Ownership of books signals familiarity with the dominant culture, and it can be put on display. On its own, the presence of books at home does not enhance skills or cognitive abilities outright, but rather indicates a scholarly or higher social status family. As upper-class families tend to have higher scholarly culture (i.e., more books at home), and as these families aspire to maintain their privileges and social status, we expect greater parental educational aspirations in families with larger libraries even after controlling for reading frequency and enjoyment of books. Thus, we propose:

Hypothesis 1: As a sign of elite membership, library size is associated positively with parental educational aspirations, even after controlling for reading and interest in books, and other socioeconomic characteristics.

Only when books are read and cherished can they enhance children's cognitive skills. Familiarity with books also may raise parents' educational aspirations and confidence in their children's ability to succeed in the educational system. This effect may be both direct and indirect. Scholarly parents are more likely to be confident in their ability to help their children successfully navigate the educational system. It is also plausible that morescholarly parents view education as more valuable than less-scholarly parents. Furthermore, we expect an indirect effect between parental reading and educational aspirations through children's own reading behavior and grades. There is comprehensive evidence that parental reading impacts children's reading habits, i.e., children of scholarly parents are more likely to read (Wollscheid 2013). If reading enhances vocabulary and cognitive skills, it is likely to improve children's academic performance. In turn, children's grades and their success in school are strong predictors of parental educational aspirations (see Figure 1). Thus, we propose:

Hypothesis 2: Reading and interest in books are associated positively with parental educational aspirations, even after controlling for library size and other socioeconomic characteristics. 
Figure 1: Conceptual model: showing main effects of children's and parents' scholarly culture on parent's educational aspirations (control variables' paths omitted)

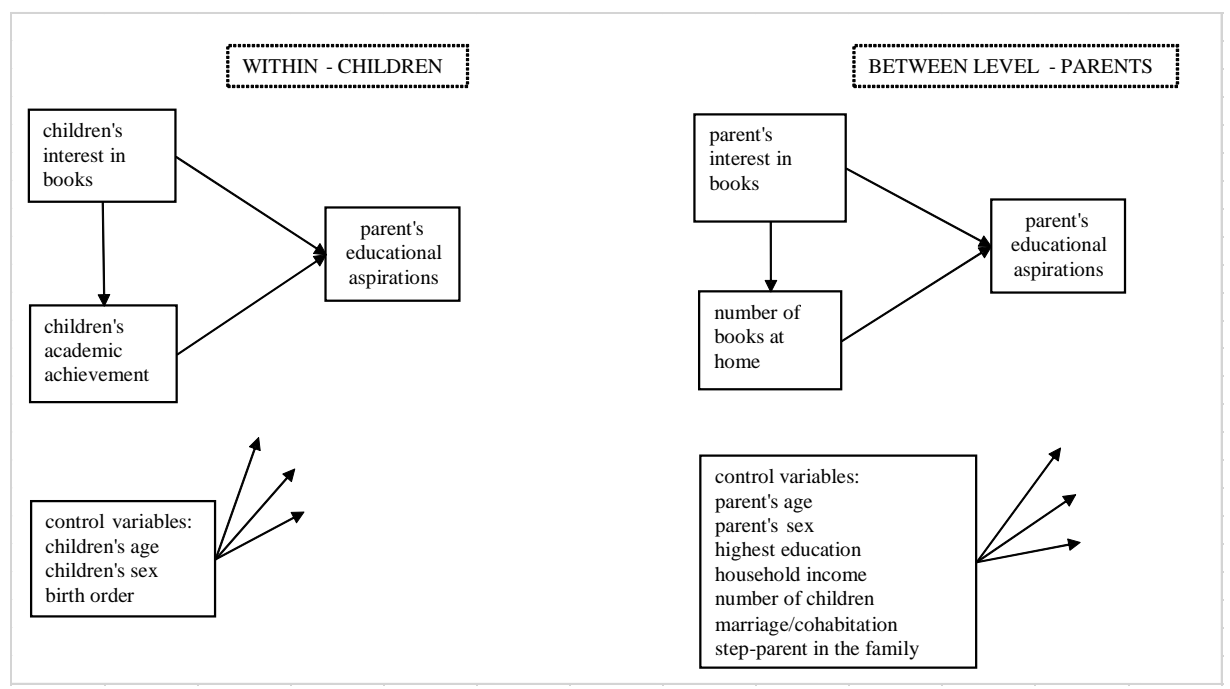

Source: Authors' diagram.

\section{Gender differences}

Furthermore, we examined whether various levels of scholarly culture explain gender differences in parental educational aspirations. Our analysis of gender differences in parental aspirations is built on two theoretical perspectives: the sociocultural approach and the stratified parenting hypothesis. The sociocultural perspective on parenting views parents as rational actors who develop goals and strategies to teach their children culturally valued skills and characteristics to enhance their life chances (Yamamoto - Holloway 2010). Stratified parenting refers to the idea that parents react to children's specific needs and engage differently with each child (Baier 2019; Baier - Lang 2019). The sociocultural and stratified parenting perspectives share many similarities, but significant differences also exist between them. The former approach focuses on parental understanding of what valuable resources are and what kind of skills a child should acquire to be successful in life. The latter examines parental reactions to children's behaviors. Although the sociocultural perspective originally was formulated to explain racial and ethnic differences, and the stratified parenting approach was developed to explain genetic influences' role in stratification outcomes, their principal ideas also can be applied to explain gender differences. 
Some empirical evidence indicates that parents tend to have higher educational aspirations for girls (DiPrete - Buchmann 2013; Schoon et al. 2007) and are more involved in their daughters' education than in that of their sons (Baker - Milligan 2016; Carter - Wojtkiewicz 2000). However, we expect that gender differences in educational aspirations may be stratified by the family's scholarly culture (Bourdieu - Passeron 1977, cited in Andres et al. 2007). The best-paying jobs at a pre-college level are male-dominated and concentrated within blue-collar fields, while women with lower education levels tend to enter service and care professions that pay relatively low wages (Dwyer 2013; Sutton et al. 2016). When considering life opportunities for their sons and daughters, parents from less-privileged backgrounds might place greater emphasis on girls' educational achievements. Indeed, some evidence indicates that women are over-represented among low-income students (Andres et al. 2007).

However, higher-status families strive to protect their social privileges. Thus, they are likely to have higher educational aspirations for both boys and girls. These families are likely to view a blue-collar profession as downward mobility and may not contemplate such options for their sons (Bernardi - GilHernández 2020). As long as the objectified scholarly culture (number of books at home) signals elite membership, we expect that in families with larger libraries, aspirations for boys' education eventually catch up with those for girls. Thus, we propose:

Hypothesis 3: In families with smaller libraries, the differences between parental educational aspirations for boys and girls will be larger than in families with larger libraries.

We also expect to find gender differences in the effect from embodied scholarly culture (reading and interest in books). Adopting the stratified parenting thesis, we expect that a child's interest in books exerts an independent effect on parental educational aspirations. It is plausible to assume that parents hold higher educational aspirations for more scholarly children who enjoy books and frequently engage in reading than for children who show no or very little interest in books. Parents might believe that more scholarly children are more inclined toward the academic route and that they would be more successful in advanced educational programs. Simultaneously, parental educational aspirations could be affected by gender norms and expectations, even for embodied scholarly culture (Schoon et al. 2007). Skills, characteristics, and educational pathways viewed as valuable for success in life for girls might differ from those for boys. Girls are overrepresented in fields such as the humanities and social sciences, which require familiarity with literary and scholarly culture. Thus, a higher level of embodied scholarly culture (higher 
frequency and engagement in reading) might be more important for girls. Thus, we propose:

Hypothesis 4: Parental educational aspirations for girls are more affected by a child's interest in books and reading than educational aspirations for boys.

Simultaneously, evidence indicates differential treatment of sons and daughters by mothers and fathers. Parents tend to develop homogamy of interest and spend more time with a child of the same sex more easily than with a child of the opposite sex (McHale et al. 2003; Mohr - DiMaggio 1995). Thus, we might expect that scholarly culture's effects will be more pronounced among mother-daughter and father-son dyads than among mother-son and father-daughter dyads. However, mothers tend to adopt less gender-differentiated treatment of children than fathers (Raley - Bianchi 2006). Therefore, we can expect that mothers will have similar aspirations for boys and girls. Thus, we propose:

Hypothesis 5: In mother-daughter and father-son dyads, we posit a stronger association between parental educational aspirations and family scholarly culture than in mother-son and father-daughter dyads.

\section{Data and methods}

\section{Data}

This study analyzed data from the first two waves of the Czech Household Panel Survey (CHPS) from 2015 and 2016, a nationally representative longitudinal survey interviewing all adult household members, including children ages 10 years and up. The households were selected using a two-stage stratified probability sampling design.

The analyses were not weighted for two reasons. First, the present study used pooled data from two CHPS waves, i.e., the weights were not constant, which is a fundamental condition for using weights in structural modeling in Mplus. Second, some authors (e.g. Gelman 2007; Rabe-Hesketh - Skrondal 2008) argue that using weights biases estimates. Given the technical limitations and lack of consensus concerning weights, the reported analyses were not weighted in this study.

The survey achieved a response rate of $42.1 \%$ in the first wave $34 \%$ of households refused to participate, and no contact was established with another $18.5 \%$ ), which is a good standard for probability sampling in the Czech Republic. Comparisons with 2011 Census data indicate that one-person households were under-represented in the survey. Calculating the response rate on the individual level is more complicated, as multiple instruments were administered to a household member. The individual CAPI response rate within the household reached (67.9\%), though slightly higher for single parents $(85.5 \%)$, explained by the fact that they are more likely to be household heads. 
The response rate for the adult PAPI questionnaire was $77.6 \%$, and for children, it was $80.3 \%$. Overall, the attrition rate between Waves 1 and 2 was $79.5 \%$ (Kudrnáčová Röschová 2019). In Wave 1,866 children filled out the PAPI questionnaire, and in Wave 2,602 children participated.

To study the link between scholarly culture and parental aspirations, we needed to merge data from Waves 1 and 2 , as some key variables were included in only one of the waves (see Section 2.2 below). Although we have full information on only 536 households, the missing values were handled in the structural model by using the maximum likelihood estimation with robust standard errors (MLR) estimator, which yields standard errors that are robust to non-normality and handles missing data with full information maximum likelihood (FIML).

\section{Variables}

The dependent variable (parental educational aspirations) was measured in Wave 1 (2015). Upon being asked, "What is the highest level of education that you would like your child [name] to achieve?" parents could choose from the following response categories: (1) elementary school; (2) secondary school without a high school diploma; (3) vocational secondary school with a high school diploma; (4) secondary general education; (5) university (bachelor's degree); (6) university (master's degree); and (7) university (doctorate). Parents answered separately for each child under age 26 living in the household and participating in full-time education.

Wave 1 also yielded data on objectified scholarly culture (home library size), which was measured by asking "How many books do you have at home?" The responses were recorded on a 10-point scale ranging from 1 (no books at home) to 10 (more than 1,500 books at home). Respondents/parents were instructed that one meter of books on a library shelf corresponded to approximately 50 books.

Embedded scholarly culture (interest in books) was measured in Wave 2 (2016) using the following four statements: 1) Reading is one of my favorite hobbies; 2) I like talking about books with others; 3) I like going to the library; and 4) I am happy when I get a book as a present. The responses were recorded on a four-point Likert scale ranging from strongly disagree to strongly agree. In addition, Wave 2 also included reading frequency ("How often do you read for pleasure?"), with a six-category response scale ranging from never to every day. As questions regarding general interest in books and reading frequency were asked of both parents and children, we elicited a measure of embedded scholarly culture for both. Given high inter-correlation (around 0.9) between these five items, a composite measure of embedded scholarly culture (interest in books) was estimated using the latent variable in the structural model for 
parents and children. All items were loaded on one factor, with factor loadings well over $0.7-0.8$.

As for the extensive set of control variables, the family's SES was measured by household income (18-point categorical variable), number of children, presence of a stepfather/stepmother in the family (dummy variable with yes $=1$, no $=0$ ), and type of family (marriage/cohabitation, with the single-parent family as a reference category). All models included the respondent's (parent's) highest education level (elementary education, lower secondary, upper secondary, or university degree) and were controlled for the parent's gender and age.

All models also incorporated several child characteristics as control variables: gender $(1=$ female, $0=$ male); age; birth order (firstborn child coded as 1 , subsequent children coded as 0 ); and academic achievement - measured as grade point average in mathematics, Czech language skills (the mother tongue - grammar and literature), and a foreign language, with higher grades indicating better performance. For detailed summary statistics of the relevant variables, please see Table OA1 in the Online Appendix ${ }^{4}$.

Except for household income, all sociodemographic variables were taken from Wave 1, when aspirations were measured. Household income was taken from Wave 2 because this measurement from Wave 1 suffered from many missing values. Even though some indicators of scholarly culture were taken from Wave 2, and aspirations were measured in Wave 1, we believe that this did not bias our analysis. Past research indicates that parental aspirations are persistent over time (Raleigh - Kao 2010). Moreover, it is plausible to expect that indicators of scholarly culture (library size and general attitudes toward books) do not change rapidly.

\section{Conceptualization of tested model}

The structural model encompassing all the relevant relationships between the variables is provided in Figure 2. In line with the hypotheses, the model posited that parental educational aspirations are associated with parents and children's interest in books and home library size. The model required the inclusion of latent variables for parents and children's interest in books, which were measured through multiple items. Following previous studies, we also posited a strong link between parental educational aspirations and parents' socioeconomic status and demographic characteristics, such as the parent's age and sex, highest education level, number of children, household income, and type of family (see Esping-Andersen 2004; Schoon et al. 2007; Spera et al. 2009). In addition to parental resources, several other child-level characteristics have been suggested as influencing parental educational aspirations, e.g., children's

${ }^{4}$ https://www.soc.cas.cz/sites/default/files/publikace/online_appendix.pdf 
academic achievement, age, gender, and birth order (see Kirk et al. 2011; Price 2008; Sosu 2014, for more).

Moreover, other important links cannot be omitted from the structural model, although they served rather as control relationships. Thus, the model further assumed that some child characteristics - such as age, gender, and birth order - also would affect a child's interest in books. For instance, girls and high-social-status students do well in school because they have a higher frequency of reading and cultural participation alongside higher educational aspirations and expectations (DiMaggio 1982; Dumais 2002; Yamamoto Brinton 2010; Breinholt - Jæger 2020). Similarly, it was posited that a few parental background characteristics - such as age, gender, highest education level, household income, and marital status - also would affect a parent's interest in books and home library size. Previous studies have demonstrated that adult highbrow cultural consumption is influenced by educational attainment, occupation, current income, gender, age, race, type of family, and/or urbanity of residence (Falk - Katz-Gerro 2016; Chorvát - Šafr 2021; Raudenská - Bašná 2021; van Hek - Kraaykamp 2015). Highly educated adults in particular are more likely to participate in all forms of cultural activities, possess vast cultural and educational resources, and read books frequently.

Figure 2: The two-level structural model of the parent's educational aspirations determination with children's and parents' characteristics

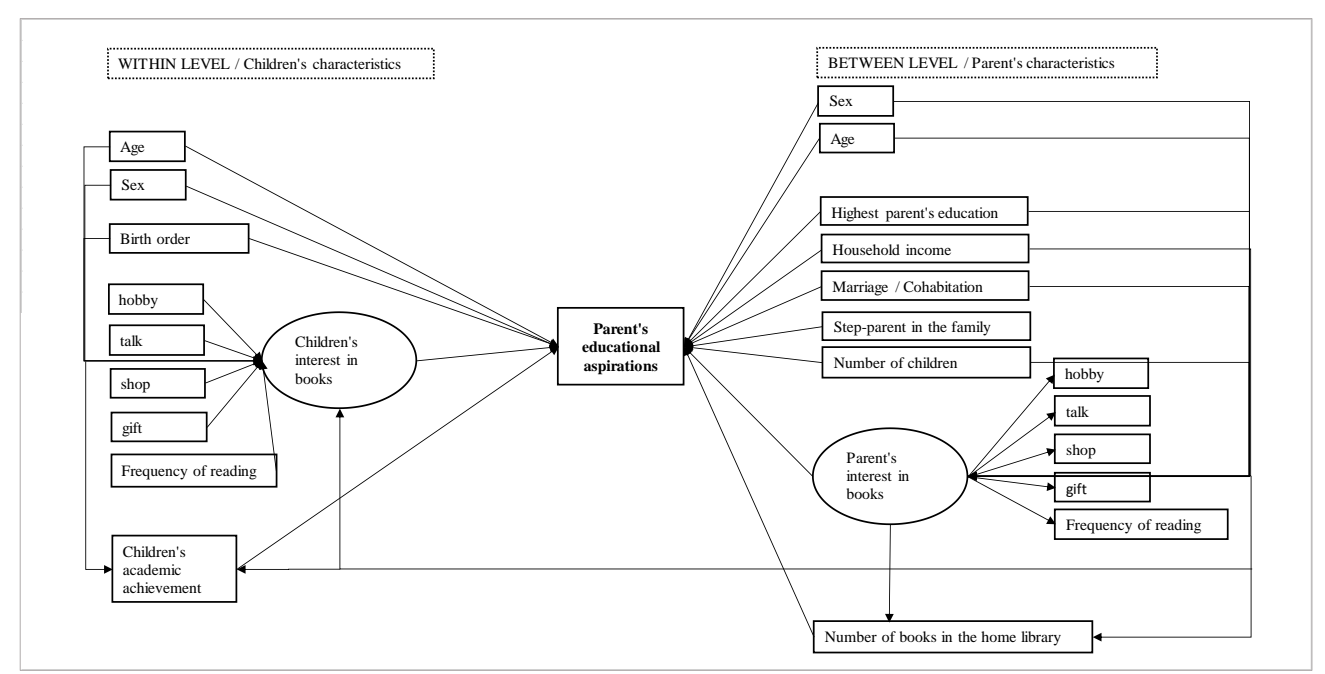

Source: Authors' diagram. 
There is also a considerable body of sociological literature on intergenerational transmission of cultural capital (Kraaykamp 2003; Kraaykamp - Van Eijck 2010; Mohr - DiMaggio 1995). Evans et al. (2010) argue that a taste for books largely is inherited. Culturally active parents are inclined toward bringing their children into contact with highbrow culture at an early age (Kraaykamp - Van Eijck 2010). As a consequence, children of culturally active parents have a more strongly culture-oriented lifestyle themselves. Therefore, we also posited that a parent's characteristics would affect a child's literary reading levels and their interest in books.

Finally, based on previous studies, we also posited that higher parental attention to books at home and parental socioeconomic status, as well as children's interest in books, benefits students' academic achievement (Bodovski - Farkas 2008; De Graaf et al. 2000; Evans et al. 2010; Jæger 2011).

\section{Methods}

To evaluate the link between children and parents' scholarly culture and parental educational aspirations, we estimated structural model parameters in various groups because the structural model handled both measurement and latent variables simultaneously, and treated error terms properly. It is necessary to emphasize that our goal was not to estimate a full causal model, for which we do not have longitudinal data. Associations between the observed and/or latent variables should not be interpreted as causal relationships (Bollen - Pearl 2013).

The model took into account that parents could report educational aspirations for more than one child and that parents from the same family are likely to have similar educational aspirations for all their children. Thus, the two-level structural model treated children (Level 1/within level) as nested within their parents (Level 2/between level) ${ }^{5}$. When variables were not constant on the model's second level (i.e., parents' characteristics were varied in the household), it was not possible to analyze a two-level structural model. Instead, we used clustered standard errors to account for parents being nested within families.

We estimated structural model parameters in various groups. First, we estimated the effect from child and parental characteristics on parental educational aspirations in general, controlling for all relevant variables. Second, we took a more detailed look at gender differences among children. We estimated the effect from girls' characteristics on parents' educational aspirations for their daughters and the effect from boys' characteristics on parents' educational aspirations for their sons.

5 Originally, we aimed to estimate a three-level structural model that would have included family on the third level, but this model was not possible to estimate in Mplus7. 
Third, we estimated structural model parameters in four other groups-dyads to determine the effect from girls' characteristics on mothers' educational aspirations for their daughters, the effect from boys' characteristics on mothers' educational aspirations for their sons, the effect from girls' characteristics on fathers' educational aspirations for their daughters, and the effect from boys' characteristics on fathers' educational aspirations for their sons, constantly controlling for all relevant variables. We were aware that it is not possible to compare particular coefficients' size and significance between various analyses due to different sample sizes. For this reason, we computed the interaction terms of gender and particular variables to confirm the statistically significant difference between the size of the coefficients of mothers and fathers or girls and boys. The results from the analyses with interaction terms are included in the Online Appendix. In this article, we commented on interactions when relevant. All models were evaluated using the comparative fit index (CFI), root mean square error of approximation (RMSEA), and Bayesian information criterion (BIC; see $\mathrm{Hu}$ - Bentler 1999). All analyses were conducted in Mplus7.

\section{Results}

\section{Descriptive statistics}

Before presenting the results from the multivariate analysis, we briefly note here the descriptive results from the frequency and mean analyses of parental educational aspirations, as provided in Table OA2 in the Online Appendix. When other factors were not controlled for, the descriptive statistics indicated that while less-educated parents formed higher educational aspirations for girls than for boys, better-educated parents had equally high aspirations for their children of either gender. Similarly, based on home library size, less-scholarly parents formed higher educational aspirations for girls, but more-scholarly parents had equally high aspirations for boys and girls. The same pattern was not detected for parents more interested in reading books or families with higher incomes, as they had higher aspirations for girls. The results also suggested that, on average, fathers had higher educational aspirations compared with mothers, particularly for daughters. Based on the child's characteristics, parents formed higher aspirations for children with higher academic performance, regardless of gender, and the child's interest in books was an important predictor of parents' aspirations, particularly for girls, i.e., if daughters did not read often or enjoy books, parents formed rather low aspirations for them. 


\section{Multivariate results}

In the structural model, we first estimated the link between parental educational aspirations and child and parental/family characteristics, as seen in Table $1^{6}$. Applying common cutoff criteria, the hypothesized model fit the data well $\left(\chi^{2}=22.58 \mathrm{df}[10], \mathrm{p}=0.0124, \mathrm{CFI}=0.989\right.$, RMSEA $\left.=0.026\right)$. Contrary to Hypotheses 1 and 2, the results did not indicate that home library size exerted an additional significant effect on formation of parental aspirations after controlling for family SES, parental characteristics, and child academic performance. Thus, the tested model did not provide any evidence that family scholarly culture contributed to parental educational aspirations. Similarly, despite our theoretical predictions, children and parents' interest in books and reading did not significantly contribute to formation of parental educational aspirations.

After controlling for socioeconomic characteristics, parents did not have any substantially different educational aspirations for boys and girls, as the descriptive statistics suggested. However, fathers had slightly higher educational aspirations for their children of either gender compared with mothers. As for other covariates, it was confirmed that children's higher age $\left(\beta_{\mathrm{M} 1}=0.345\right)$ and academic achievement $\left(\beta_{\mathrm{M} 1}=0.389\right)$, as well as parents' higher education level $\left(\beta_{\mathrm{M} 1}=0.183\right)$ and household income $\left(\beta_{\mathrm{M} 1}=0.075\right)$, significantly enhanced parental educational aspirations (for similar results, see Spera et al. 2009). In particular, the parents had higher educational aspirations when their children's school grades were higher.

Next, we re-estimated the same model for daughters and sons. The results did not reveal any substantial differences in general patterns for girls and boys, with two exceptions. First, the link between household income and educational aspirations was significant only among girls. Second, library size was significant only for educational aspirations for boys. Nevertheless, it is necessary to keep in mind that the separate analyses did not directly test these gender differences. Thus, in the supplementary analysis, we re-estimated the same model with the interaction effect between children's gender, household income, and home library size (see Table OA3 in the Online Appendix). These supplementary models did not confirm significant gender differences for household income $\left(\mathrm{B}_{\text {interaction [girl } \mathrm{x} \text { household income] }}=-0.013\right.$, S.E. $=0.030, \mathrm{p}$ value $=$ $0.656)$, but revealed marginally significant gender differences for number of books at home $\left(\mathrm{B}_{\text {interaction } \text { [girl } \mathrm{x} \text { library size] }}=-0.089\right.$, S.E. $=0.050, \mathrm{p}$ value $\left.=0.076\right)$.

A closer inspection of the interaction effects indicates, in line with Hypothesis 3, that in families with smaller libraries, parents tended to have

\footnotetext{
${ }^{6}$ For the sake of clarity, Tables 1-3 reported only unstandardized and standardized regression coefficients of the structural model predicting parental educational aspirations. Regression coefficients of full structural models tested in various groups (i.e., all causal paths) can be found in the Online Appendix (Tables OA4-OA10).
} 
higher educational aspirations for girls than for boys. However, in families with larger libraries, educational aspirations for sons caught up with those for girls. Despite the rather small effect size, this finding corroborated our theoretical reasoning, as we have suggested that gender differences in educational aspirations may be stratified by family scholarly culture. It is also generally in line with Mohr and DiMaggio's (Mohr - DiMaggio 1995) finding that the largest gender differences in cultural capital are in blue-collar families. Highersocial-status families strive to protect their social privileges and may seek educational credentials - as a sign of elite membership - for both sons and daughters. However, among lower-social-status families, parents may believe that boys may do well even without higher education, but view education as more essential for girls.

The idea that gender differences are stratified by the family's SES is supported by the fact that very similar patterns also were observed with parental education $\left(\mathrm{B}_{\text {interaction [girl } \mathrm{x} \text { parental education] }}=-0.219\right.$, S.E. $=0.100, \mathrm{p}$ value $=$ $0.028)$ and child academic achievement $\left(\mathrm{B}_{\text {interaction [girl } \mathrm{x} \text { academic achievement] }}=-0.553\right.$, S.E. $=0.164, \mathrm{p}$ value $=0.001)$. While higher-educated parents hold similar educational aspirations for sons as well as for daughters, less-educated parents have much higher educational aspirations for their daughters than for their sons. Similarly, it seems that parents tend to have higher educational aspirations for girls even if their daughters do not perform well in school. For boys, parental educational aspirations are linked more closely to their school grades.

Thus, our analysis suggests that even though the overall effect from objectified scholarly culture (family library size) was not significant, it is still important for diminishing gender differences in educational aspirations. Even after controlling for several socioeconomic indicators, the number of books at home significantly contributed to the narrowing gap between parental educational aspirations for boys and girls. Simultaneously, contrary to Hypothesis 4, we did not find any independent effect from embedded scholarly culture on either sons or daughters. 
Table 1 : Unstandardized and standardized regression coefficients of the structural model predicting parents educational aspirations

\begin{tabular}{|c|c|c|c|c|c|c|c|c|c|}
\hline \multirow{3}{*}{ Children's characteristics } & \multicolumn{2}{|c|}{ Children's characteristics } & \multicolumn{4}{|c|}{ Boys's characteristics } & \multicolumn{3}{|c|}{ Girls's characteristics } \\
\hline & B & Beta* & B & \multicolumn{2}{|r|}{ S.E. } & \multirow[t]{2}{*}{ Beta* } & \multirow[t]{2}{*}{$\mathrm{B}$} & \multirow[t]{2}{*}{ S.E. } & \multirow[t]{2}{*}{ Beta* } \\
\hline & & & & & & & & & \\
\hline Children's sex & 0.100 & 0.103 & 0.029 & - & - & - & - & - & - \\
\hline Children's age & $0.118^{* * *}$ & 0.020 & 0.345 & $0.184^{* * *}$ & 0.029 & 0.517 & $0.076^{* *}$ & 0.024 & 0.232 \\
\hline Birth order & 0.121 & 0.096 & 0.035 & 0.120 & 0.148 & 0.034 & 0.163 & 0.139 & 0.050 \\
\hline Academic achievement & $0.694^{* * *}$ & 0.096 & 0.389 & $1.049^{* * *}$ & 0.115 & 0.614 & $0.350^{* *}$ & 0.130 & 0.194 \\
\hline Children's interest in books & 0.072 & 0.082 & 0.042 & 0.019 & 0.134 & 0.010 & 0.147 & 0.099 & 0.089 \\
\hline \multicolumn{10}{|l|}{ Parents' characteristics } \\
\hline Parent's sex & $-0.151^{\dagger}$ & 0.088 & -0.043 & -0.166 & 0.123 & -0.046 & -0.163 & 0.108 & -0.048 \\
\hline Parent's age & 0.009 & 0.012 & 0.033 & -0.006 & 0.016 & -0.023 & 0.021 & 0.014 & 0.080 \\
\hline Parent's highest education & $0.374^{* * *}$ & 0.073 & 0.183 & $0.431^{* * *}$ & 0.093 & 0.208 & $0.296^{* * *}$ & 0.090 & 0.149 \\
\hline Household income & $0.050^{*}$ & 0.025 & 0.075 & 0.020 & 0.033 & 0.029 & $0.073^{*}$ & 0.030 & 0.117 \\
\hline Number of children & 0.043 & 0.055 & 0.025 & 0.123 & 0.098 & 0.067 & 0.007 & 0.066 & 0.004 \\
\hline Marriage & -0.174 & 0.187 & -0.046 & -0.203 & 0.255 & -0.052 & -0.255 & 0.225 & -0.069 \\
\hline Cohabitation & -0.004 & 0.245 & -0.001 & 0.098 & 0.353 & 0.021 & -0.237 & 0.304 & -0.045 \\
\hline $\begin{array}{l}\text { Stepfather/stepmother in the } \\
\text { family }\end{array}$ & -0.257 & 0.180 & -0.053 & -0.264 & 0.238 & -0.056 & -0.220 & 0.239 & -0.044 \\
\hline Home library size & 0.062 & 0.039 & 0.061 & $0.122^{*}$ & 0.049 & 0.118 & 0.004 & 0.047 & 0.004 \\
\hline Parent's interest in books & 0.017 & 0.056 & 0.010 & -0.002 & 0.075 & -0.001 & 0.057 & 0.071 & 0.034 \\
\hline $\mathrm{N}$ (clusters) & & 919 & & & 559 & & & 578 & \\
\hline
\end{tabular}

Source: CHPS (2015-2016), authors' own calculations. Levels of statistical significance: ${ }^{* * *} \mathrm{p}<0.001,{ }^{* *} \mathrm{p}<0.01,{ }^{*} \mathrm{p}<0.05,{ }^{\dagger} \mathrm{p}<0.1 .{ }^{*} \mathrm{~B}=$ unstandardized regression coefficient, Beta $=$ standardized regression coefficients

Note 1: Model fit - Chi-square $=22.578(10 \mathrm{df}), \mathrm{p}=0.0124, \mathrm{CFI}=0.989, \mathrm{RMSEA}=0.026, \mathrm{SRMR}=0.008, \mathrm{BIC}=21,172.444($ type $=$ complex $)$ 
Note 2: Model fit (multi-sample analysis) - Chi-square $=32.697(16 \mathrm{df}), \mathrm{p}=0.0081, \mathrm{CFI}=0.986, \mathrm{RMSEA}=$ $0.034, \mathrm{SRMR}=0.010, \mathrm{BIC}=21,521.916($ type $=$ complex $)$

${ }^{* *}$ Corrections to the standard errors and chi-square test of model fit that took into account non-independence of observations and unequal probability of selection were obtained by using the TYPE=COMPLEX option of the ANALYSIS command. TYPE=TWOLEVEL option couldn't be used because the variables weren't constant on the second level of the model; mothers' and fathers' (parents') characteristics were varied in the household.

We then shifted our attention toward parents' gender. Again, we presented separate analyses for mothers and fathers reporting on sons and daughters for simplicity and easier interpretation. However, we also estimated parameters of the model with interaction effects to test whether the observed differences were significant (see Table OA3 in the Online Appendix). In Hypothesis 5, we suggested that mothers and fathers might adopt different aspirations for sons and daughters. Table 2 suggests that the link between mothers' educational aspirations and children's academic achievement or interest in books indeed functioned differently for boys and girls. In the case of a child's interest in books, the link was significant only in the model for daughters. This result supports the idea that scholarly interests are more important to mothers and girls. However, the supplementary model with interaction effect did not support this idea because the interaction effect between the child's gender and interest in books was not significant $\left(B_{\text {interaction [girl } \mathrm{x} \text { interest in books] }}=0.094\right.$, S.E. $=0.187$, $\mathrm{p}$ value $=0.615$; see Online Appendix). In the case of academic achievement $\left(B_{\text {interaction [girl } x \text { school achievement }]}=-0.583\right.$, S.E. $=0.179, \mathrm{p}$ value $\left.=0.001\right)$, Table 2 indicates that student's performance was a stronger predictor for mothers' educational aspirations with sons than with daughters. Mothers hold relatively high educational aspirations even for under-performing daughters. However, if the mother's son did not get good grades, the mother was more likely to lower her educational aspirations. As for other characteristics, no gender differences were observed among mothers.

The separate analyses in Table 2 suggest that fathers' educational aspirations for sons were affected by family library size and the father's education. In contrast, fathers' aspirations for daughters were linked to household income. However, in a re-estimated supplementary model with interaction effect, only the interaction term between the father's education and the child's gender was significant $\left(B_{\text {interaction [girl } x \text { father's education] }}=-0.344\right.$, S.E. $=$ 0.138 , $\mathrm{p}$ value $=0.013$ ). Again, less-educated fathers placed a higher emphasis on their daughters' education than that of their sons, while more-educated fathers believe that even sons should achieve higher educational credentials. Our data also demonstrated that fathers' educational aspirations for their daughters were less affected by the child's school performance than were their aspirations for their sons $\left(B_{\text {interaction [girl } \mathrm{x} \text { academic achievement] }}=-0.521\right.$, S.E. $=0.220$, $\mathrm{p}$ value $=0.018$ ). 
Table 2: Unstandardized and standardized regression coefficients of the structural model predicting mothers and fathers' educational aspirations

\begin{tabular}{|c|c|c|c|c|c|c|c|c|c|c|c|c|}
\hline & \multicolumn{6}{|c|}{ Mothers' aspirations } & \multicolumn{6}{|c|}{ Fathers' aspirations } \\
\hline & \multicolumn{3}{|c|}{ Girls' characteristics } & \multicolumn{3}{|c|}{ Boys' characteristics } & \multicolumn{3}{|c|}{ Girls' characteristics } & \multicolumn{3}{|c|}{ Boys' characteristics } \\
\hline & B & S.E. & Beta* & B & S.E. & Beta* & B & S.E. & Beta* & B & S.E. & Beta* \\
\hline \multicolumn{13}{|c|}{ Children's characteristics (within-level) } \\
\hline Children's age & $0.068^{* * *}$ & 0.017 & 0.419 & $0.145^{* * *}$ & 0.033 & 0.629 & 0.032 & 0.030 & 0.100 & $0.129^{* * *}$ & 0.031 & 0.650 \\
\hline Birth order (the first one) & $0.202^{\dagger}$ & 0.117 & 0.124 & $0.323^{*}$ & 0.142 & 0.144 & 0.062 & 0.177 & 0.019 & 0.059 & 0.156 & 0.029 \\
\hline Academic achievement & $0.261^{* * *}$ & 0.060 & 0.276 & $0.932^{* * *}$ & 0.137 & 0.823 & $0.363^{*}$ & 0.149 & 0.215 & $0.793^{* * *}$ & 0.153 & 0.818 \\
\hline \multicolumn{13}{|c|}{ Parents' characteristics (between-level) } \\
\hline Parent's age & 0.007 & 0.016 & 0.029 & 0.011 & 0.018 & 0.049 & $0.041^{*}$ & 0.016 & 0.180 & -0.016 & 0.016 & -0.082 \\
\hline Parent's highest education & $0.400^{* * *}$ & 0.102 & 0.234 & $0.461^{* * *}$ & 0.111 & 0.297 & $0.254^{\dagger}$ & 0.135 & 0.133 & $0.687^{* * *}$ & 0.123 & 0.414 \\
\hline Household income & $0.066^{*}$ & 0.032 & 0.133 & 0.024 & 0.034 & 0.050 & $0.106^{*}$ & 0.053 & 0.147 & 0.034 & 0.048 & 0.056 \\
\hline Number of children & 0.072 & 0.075 & 0.044 & 0.068 & 0.096 & 0.046 & -0.078 & 0.088 & -0.059 & 0.105 & 0.099 & 0.069 \\
\hline Marriage & -0.282 & 0.219 & -0.096 & 0.058 & 0.224 & 0.022 & 0.114 & 0.435 & 0.023 & -0.158 & 0.551 & -0.045 \\
\hline $\mathrm{N}$ (clusters) & & 483 & & & 451 & & & 279 & & & 280 & \\
\hline
\end{tabular}

Source: CHPS (2015-2016), authors' own calculations. Levels of statistical significance: ${ }^{* * *} \mathrm{p}<0.001,{ }^{* *} \mathrm{p}<0.01,{ }^{*} \mathrm{p}<0.05,{ }^{\dagger} \mathrm{p}<0.1 .{ }^{*} \mathrm{~B}=$ unstandardized regression coefficient, Beta $=$ standardized regression coefficients

Note 1: Model fit - Chi-square $=142.52(66 \mathrm{df}), \mathrm{p}=0.0000, \mathrm{CFI}=0.969, \mathrm{RMSEA}=0.045, \mathrm{SRMR}_{\text {(within })}=0.032, \mathrm{SRMR}_{(\text {between })}=0.024, \mathrm{BIC}=13,340.7$ (type=twolevel)

Note 2: Model fit - Chi-square $=120.09(66 \mathrm{df}), \mathrm{p}=0.0001, \mathrm{CFI}=0.977, \mathrm{RMSEA}=0.038, \mathrm{SRMR}_{\text {(within) }}=0.057, \mathrm{SRMR}_{\text {(between) }}=0.021, \mathrm{BIC}=12,520.6$ (type=twolevel) 
Note 3: Model fit - Chi-square $=29.959(8 \mathrm{df}), \mathrm{p}=0.0002, \mathrm{CFI}=0.900, \mathrm{RMSEA}=0.088, \mathrm{SRMR}=0.019$, $\mathrm{BIC}=4,342.7$ (type $=$ complex)

Note 4: Model fit - Chi-square $=147.56(66 \mathrm{df}), \mathrm{p}=0.0000, \mathrm{CFI}=0.944, \mathrm{RMSEA}=0.059, \mathrm{SRMR}_{\text {(within) }}=$ $0.076, \mathrm{SRMR}_{\text {(between) }}=0.032, \mathrm{BIC}=7,906.8$ (type $=$ twolevel)

As for other covariates, the results are congruent with previous research. As in past studies (e.g., Spera et al. 2009), a positive association between children's academic achievement, parents' highest education level, and higher parental aspirations for children's education was observed in the CHPS data. We tried to take into account many other relevant explanatory variables at the child and household levels to represent heterogeneity in family backgrounds, but neither the child's birth order and reading habits - nor the parent's age, number of children, type of family, or parental interest in books - compensated for the effect from the parent's education level and the child's academic achievement.

However, we found several substantial gender differences between both mothers and fathers and girls and boys. Regarding children, the results indicated that in the formation of educational aspirations for daughters, parents' education level and household income were significant; however, girls' ages, school grades, and reading habits also were significant determinants of parental educational aspirations. Similarly, in the formation of educational aspirations for sons, parents' education level, household income, and home library size were significant, but boys' school grades primarily were the strongest predictor of parental educational aspirations. In this way, parents tend to form higher educational aspirations regardless of their daughters' school grades or their own education levels, whereas with boys, the parents were more concerned about their academic achievements, with educational and family scholarly culture also being significant. Both parents formed their higher educational aspirations when their sons were older, indicating that they might wait for their sons' academic readiness, while considering their cognitive and non-cognitive skills.

Finally, we also posited that a child's demographic characteristics and parental scholarly culture would affect a child's interest in books. The results confirmed these links as being strongly significant, as were the effects from children's characteristics and parental education on children's academic achievement (see Table OA1 in the Online Appendix). Similarly, the results demonstrated strong associations among individual parental characteristics (e.g., gender, age, education, and type of family), interest in books, and home library size. 


\section{Discussion and conclusion}

Until recently, social stratification research has focused on family scholarly culture's effect on children's educational attainment or cognitive skills (De Graaf et al. 2000; Jæger - Breen 2016; Breinholt - Jæger 2020). However, the present study focused on family scholarly culture's effect on parental educational aspirations, distinguishing between objectified scholarly culture (library size) as a sign of elite membership and embodied scholarly culture (reading and interest in books) as a means of cognitive and skill enhancement. Moreover, it focused on gender differences in scholarly culture's role.

Using parent-child dyads from the CHPS (2015-2016), we found little evidence that scholarly culture contributes to parental educational aspirations. A proposed model that controlled for familial socioeconomic characteristics did not demonstrate an independent effect from library size or reading interests on parental educational aspirations. This result is in line with Van de Werfhorst - Hofstede (2007), who found a significant link between parental participation in highbrow culture and children's school performance, but not educational aspirations. However, the present study revealed important gender differences. We hypothesized that scholarly culture would narrow the gender gap in educational aspirations. In particular, we expected that smaller library size would be linked to a larger gender gap, i.e., greater emphasis on daughters' rather than sons' educational achievements. Given that occupations typically associated with females at the non-college level offer relatively low wages and that women's financial returns from education are higher (DiPrete - Buchmann 2013; Mysíková 2018), even parents with lower social status might put more emphasis on girls' school achievement. However, we expected that families with larger libraries would put equal emphasis on their sons and daughters' education, positing that if larger libraries are a sign of elite membership, these families might strive to protect their social privileges. Our data confirmed this expectation about narrowing the gender gap and diminishing girls' advantage in higher-social-status families. Similar patterns also were observed with parental education. Parents, particularly fathers, with higher education levels had similar aspirations for their boys and their girls.

Furthermore, we adopted the idea of stratified parenting and also expected that children's scholarly interests (interest in books and reading) would be associated significantly with parental educational aspirations, particularly for girls. However, we did not find a significant link between parental educational aspirations and child or parental interest in books or reading habits.

Regarding parents' sex, the outcomes suggested that parents form their educational aspirations for sons and daughters differently. First, fathers had slightly higher educational aspirations for their children than mothers. It also 
seems that whereas mothers considered a child's reading interest closely, fathers took into account the presence of books at home-indicating a scholarly, higher-social-status family -in forming higher educational aspirations for their children. This might suggest that fathers could be more responsive to the objectified dimension of cultural capital with a symbolic function in the formation of their educational aspirations while considering the household's socioeconomic and sociocultural situation as a whole.

Importantly, even though we did to find a significant overall link between parental aspirations and scholarly culture, our results indicate that such culture has important implications for gender differences. In more scholarly families, boys catch up with girls, and parents aspirations for boys and girls are both high. The relatively weak link between scholarly culture and parental aspirations suggests that parental aspirations are not just a direct expression of cultural capital. In less-scholarly families, formation of parental aspirations seems to be more in line with rational choice theory. Given the lower financial returns to education among men, less-scholarly families are more accepting of non-college tracks for their sons. However, they understand that education benefits girls more significantly, and they are more likely to steer their daughters toward college. Similar rationale might be seen in the finding that parents hold higher educational aspirations even for underperforming girls, but tend to lower them for underperforming boys.

In more-scholarly families, the rational choice framework seems to have lower explanatory power. Despite gender differences in financial returns to education, the gender gap in aspirations is lower, and more scholarly parents want even their sons to pursue higher education. In this case, aspirations might be more of an expression of cultural capital, and diplomas might be valued more for their symbolic meaning and prestige.

Nevertheless, our findings are subject to several limitations. The first was the limited scope of the variables included in the study. Scholarly cultural indicators may be confounded by other variables that are not included in the analysis. It is likely that psychological moderators - such as a child's selfesteem, locus of control, or emotional and behavioral disposition, or parental educational or work values - also could be related to parental educational aspirations. However, these lie beyond the present study's scope. Moreover, the reading interest indicator partly could be a proxy for parental educational/human capital, such as reading skills or ability, which is not captured fully by parents' education level. Also, the data did not include information about types of books that families own. It is likely that not only do number of books matter, but also their content (popular, serious, or practical) (De Graaf De Graaf 2002). Another problem could be a reverse causality between family scholarly culture and parental educational aspirations for children. Higher- 
aspiring parents are more likely to buy books and other educational resources; thus, higher parental expectations also can stimulate reading and home literacy environment (see, for instance Davis-Kean 2005). It was not possible to examine these processes longitudinally, which would have provided a better test of our hypotheses. Therefore, the results from this analysis are suggestive, rather than conclusive. Finally, single-country analysis neglects any cultural variability in the investigated effects; therefore, these issues call for replication of this analysis with data that address these deficiencies.

Dana Hamplová is a senior scientist in the Institute of Sociology, Czech Academy of Sciences. Her research focuses on social stratification, family behaviors, health and values, and religion. She authored or co-authored a number of books and her works are published in the top journal of the field such as Demography, Journal of Happiness Studies, Journal of Ethnic and Migration Studies.

ORCID: 0000-0002-4212-6475

Petra Raudenská works as a senior researcher at the Institute of Sociology of the Czech Academy Sciences. Her research interests are survey methodology, educational inequality, human capital, life satisfaction, and human values. She authored or co-authored a number of books and her works are published in Social Science Research, Poetics, International Sociology, Innovation: The European Journal of Social Science Research.

ORCID: 0000-0002-0330-139X

\section{REFERENCES}

AGGER, C. - MEECE, J. - BYUN, S.-Y., 2018: The Influences of Family and Place on Rural Adolescents' Educational Aspirations and Post-Secondary Enrollment. Journal of Youth and Adolescence 47(12): 2554-2568. https://doi.org/10.1007/s10964-018-0893-7

ANDRES, L. - ADAMUTI-TRACHE, M. - YOON, E.-S. - PIDGEON, M. THOMSEN, J. P., 2007: Educational Expectations, Parental Social Class, Gender, and Postsecondary Attainment: A 10-Year Perspective. Youth \& Society 39(2): 135-163. https://doi.org/10.1177/0044118X06296704

BAIER, T., 2019: Does Sibling and Twin Similarity in Cognitive Ability Differ by Parents' Education? ZfF-Zeitschrift für Familienforschung/Journal of Family Research 31(1): 58-82. https://doi.org/10.3224/zff.v31i1.04

BAIER, T. - LANG, V., 2019: The Social Stratification of Environmental and Genetic Influences on Education: New Evidence Using a Register-Based Twin Sample. Sociological Science 6(6): 143-171. https://doi.org/10.15195/v6.a6

BAKER, M. - MILLIGAN, K., 2016: Boy-Girl Differences in Parental Time Investments: Evidence from Three Countries. Journal of Human Capital 10(4): 399441. https://doi.org/10.1086/688899 
BERNARDI, F. - GIL-HERNÁNDEZ, C. J., 2020: The Social-Origins Gap in Labour Market Outcomes: Compensatory and Boosting Advantages Using a Micro-Class Approach. European Sociological Review. https://doi.org/10.1093/esr/jcaa034

BLAABÆK, E. H., 2020: Reading when the Sun does Not Shine: The Effect of Reading on Children's Academic Performance. Research in Social Stratification and Mobility 67. https://doi.org/10.1016/j.rssm.2020.100485

BODOVSKI, K. - FARKAS, G., 2008: "Concerted Cultivation" and Unequal Achievement in Elementary School. Social Science Research 37(3): 903-919. https://doi.org/10.1016/j.ssresearch.2008.02.007

BOLLEN, K. A. - PEARL, J., 2013: Eight Myths about Causality and Structural Equation Models. Pp. 301-328. In: S. Morgan (eds.): Handbook of Causal Analysis for Social Research. Springer. https://doi.org/10.1007/978-94-007-6094-3_15

BRANIGAN, A. R. - MCCALLUM, K. J. - FREESE, J., 2013: Variation in the Heritability of Educational Attainment: An International Meta-Analysis. Social Forces 92(1): 109-140. https://doi.org/10.1093/sf/sot076

BREINHOLT, A. - JÆGER, M. M., 2020: How does Cultural Capital Affect Educational Performance: Signals or Skills? The British Journal of Sociology 71(1): 28-46. https://doi.org/10.1111/1468-4446.12711

CARTER, R. S. - WOJTKIEWICZ, R. A., 2000: Parental Involvement with Adolescents' Education: Do Daughters or Sons get More Help? Adolescence 35(137): 29-44.

DAVIS-KEAN, P. E., 2005: The Influence of Parent Education and Family Income on Child Achievement: The Indirect Role of Parental Expectations and the Home Environment. Journal of Family Psychology 19(2): 294-304. https://doi.org/10.1037/0893-3200.19.2.294

DE GRAAF, N. D. - DE GRAAF, P. M., 2002: Formal and Popular Dimensions of Cultural Capital: Effects on Children's Educational Attainment. The Netherlands' Journal of Social Sciences 38(2): 167-183. http://hdl.handle.net/2066/62482

DE GRAAF, N. D. - DE GRAAF, P. M. - KRAAYKAMP, G., 2000: Parental Cultural Capital and Educational Attainment in the Netherlands: A Refinement of the Cultural Capital Perspective. Sociology of Education 73(2): 92-111. https://doi.org/10.2307/2673239

DEWITT, J. - ARCHER, L. - OSBORNE, J. - DILLON, J. - WILLIS, B. - WONG, B., 2011: High Aspirations but Low Progression: The Science Aspirations-Careers Paradox Amongst Minority Ethnic Students. International Journal of Science and Mathematics Education 9(2): 243-271. https://doi.org/10.1007/s10763-010-9245-0

DIMAGGIO, P., 1982: Cultural capital and school success: The impact of status culture participation on the grades of US high school students. American Sociological Review 47(2): 189-201. https://doi.org/10.2307/2094962

DIMAGGIO, P., 1997: Culture and cognition. Annual Review of Sociology 23(1): $263-$ 263. https://doi.org/10.1146/annurev.soc.23.1.263

DOLLMANN, J. - WEIßMANN, M., 2020: The Story after Immigrants' Ambitious Educational Choices: Real Improvement or Back to Square One? European Sociological Review 36(1): 32-47. https://doi.org/10.1093/esr/jcz042 
DWYER, R. E., 2013: The Care Economy? Gender, Economic Restructuring, and Job Polarization in the US Labor Market. American Sociological Review 78(3): 390416. https://doi.org/10.1177/0003122413487197

ESPING-ANDERSEN, G., 2004: Untying the Gordian Knot of Social Inheritance. Research in Social Stratification and Mobility 21(1): 115-138. https://doi.org/10.1016/S0276-5624(04)21007-1

EVANS, M. - KELLEY, J. - SIKORA, J., 2014: Scholarly Cculture and Academic Performance in 42 Nations. Social Forces 92(4): 1573-1605. https://doi.org/10.1093/sf/sou030

EVANS, M. - KELLEY, J. - SIKORA, J. - TREIMAN, D. J., 2010: Family Scholarly Culture and Educational Success: Books and Schooling in 27 Nations. Research in Social Stratification and Mobility 28(2): 171-197. https://doi.org/10.1016/j.rssm.2010.01.002

EVANS, M. - KELLEY, J. - SIKORA, J. - TREIMAN, D. J., 2015: Scholarly Culture and Occupational Success in 31 Societies. Comparative Sociology 14(2): 176-218. https://doi.org/10.1163/15691330-12341345

FALK, M. - KATZ-GERRO, T., 2016: Cultural Participation in Europe: Can we Identify Common Determinants? Journal of Cultural Economics 40(2): 127-162. https://doi.org/10.1007/s10824-015-9242-9

FAN, W. - WILLIAMS, C. M., 2010: The Effects of Parental Involvement on Students' Academic Self-Efficacy, Engagement and Intrinsic Motivation. Educational Psychology 30(1): 53-74. https://doi.org/10.1080/01443410903353302

GAO, F. - NG, J. C. K., 2017: Studying Parental Involvement and University Access and Choice: An 'Interacting Multiple Capitals' Model. British Educational Research Journal 43(6): 1206-1224. https://doi.org/10.1002/berj.3298

GELMAN, A., 2007: Struggles with Survey Weighting and Regression Modeling. Statistical Science 22(2): 153-164. https://doi.org/10.1214/088342306000000691

HOLMES, K. - GORE, J. - SMITH, M. - LLOYD, A., 2018: An Integrated Analysis of School Students' Aspirations for STEM Careers: Which Student and School Factors are most Predictive? International Journal of Science and Mathematics Education 16(4): 655-675. https://doi.org/10.1007/s10763-016-9793-Z

HU, L. T. - BENTLER, P. M., 1999: Cutoff Criteria for Fit Indexes in Covariance Structure Analysis: Conventional Criteria Versus New Alternatives. Structural Equation Modeling: A Multidisciplinary Journal 6(1): 1-55. https://doi.org/10.1080/10705519909540118

CHORVÁT, I. - ŠAFR, J., 2021: Vol’nočasové aktivity v Slovenskej a Českej republike: sú faktory, ktoré ich ovplyvňujú, národne špecifické? Sociológia 53(2): 147 179. https://doi.org/10.31577/sociologia.2021.53.2.6

JÆGER, M. M., 2011: Does Cultural Capital Really Affect Academic Achievement? New Evidence from Combined Sibling and Panel Data. Sociology of Education 84(4): 281-298. https://doi.org/10.1177/0038040711417010

JÆGER, M. M. - BREEN, R., 2016: A Dynamic Model of Cultural Reproduction. American Journal of Sociology 121(4): 1079-1115. https://doi.org/10.1086/684012 
JÆGER, M. M. - HOLM, A., 2007: Does Parents' Economic, Cultural, and Social Capital Explain the Social Class Effect on Educational Attainment in the Scandinavian Mobility Regime? Social Science Research 36(2): 719-744. https://doi.org/10.1016/j.ssresearch.2006.11.003

JEYNES, W. H., 2007: The Relationship between Parental Involvement and Urban Secondary School Student Academic Achievement: A Meta-Analysis. Urban Education 42(1): 82-110. https://doi.org/10.1177/0042085906293818

KELLEY, J. - EVANS, M., 2000: Cultural Resources and Educational Success: The Beaux Arts Versus Scholarly Culture. Australian Social Monitor 3(2): 41-48. https://search.informit.org/doi/10.3316/ielapa.709431154897872

KIRK, C. M. - LEWIS-MOSS, R. K. - NILSEN, C. - COLVIN, D. Q., 2011: The Role of Parent Expectations on Adolescent Educational Aspirations. Educational Studies 37(1): 89-99. https://doi.org/10.1080/03055691003728965

KRAAYKAMP, G., 2003: Literary Socialization and Reading Preferences. Effects of Parents, the Library, and the School. Poetics 31(3-4): 235-257. https://doi.org/10.1016/S0304-422X(03)00033-0

KRAAYKAMP, G. - VAN EIJCK, K., 2010: The Intergenerational Reproduction of Cultural Capital: A Threefold Perspective. Social forces 89(1): 209-231. https://doi.org/10.1353/sof.2010.0087

LAZARIDES, R. - VILJARANTA, J. - AUNOLA, K. - PESU, L. - NURMI, J.-E., 2016: The Role of Parental Expectations and Students' Motivational Profiles for Educational Aspirations. Learning and Individual Differences 51(October): 29-36. https://doi.org/10.1016/j.lindif.2016.08.024

LUCAS, S. R., 2001: Effectively Maintained Inequality: Education Transitions, Track Mobility, and Social Background Effects. American Journal of Sociology 106(6): 1642-1690. https://doi.org/10.1086/321300

MATĚJŮ, P. - SMITH, M. L., 2009: The Perceived Value of Education and Educational Aspirations in the Czech Republic: Changes in the Determination of Educational Aspirations between 1989 and 2003. Comparative Education Review 53(1): 13-39. https://doi.org/10.1086/593151

MCHALE, S. M. - CROUTER, A. C. - WHITEMAN, S. D., 2003: The Family Contexts of Gender Development in Childhood and Adolescence. Social Development 12(1): 125-148. https://doi.org/10.1111/1467-9507.00225

MOHR, J. - DIMAGGIO, P., 1995: The Intergenerational Transmission of Cultural Capital. Research in Social Stratification and Mobility 14(-): 167-200.

MOOTE, J. - ARCHER, L. - DEWITT, J. - MACLEOD, E., 2020: Comparing Students' Engineering and Science Aspirations from Age 10 to 16: Investigating the Role of Gender, Ethnicity, Cultural Capital, and Attitudinal Factors. Journal of Engineering Education 109(1): 34-51. https://doi.org/10.1002/jee.20302

MULLAN, K., 2010: Families that Read: A Time-Diary Analysis of Young People's and Parents' Reading. Journal of Research in Reading 33(4): 414-430. https://doi.org/10.1111/j.1467-9817.2010.01438.x

MYSÍKOVÁ, M., 2018: Mzdy a př́immové nerovnosti. Pp. 23-38. In: D. Hamplová and T. Katrňák (eds.): Na vzdělání záleží. 
PARK, H., 2008: Home Literacy Environments and Children's Reading Performance: A Comparative Study of 25 Countries. Educational Research and Evaluation 14(6): 489-505. https://doi.org/10.1080/13803610802576734

PRICE, J., 2008: Parent-Child Quality Time does Birth Order Matter? Journal of Human Resources 43(1): 240-265. https://doi.org/10.3368/jhr.43.1.240

RALEIGH, E. - KAO, G., 2010: Do Immigrant Minority Parents have more Consistent College Aspirations for their Children? Social Science Quarterly 91(4): 1083-1102. https://doi.org/10.1111/j.1540-6237.2010.00750.x

RALEY, S. - BIANCHI, S., 2006: Sons, Daughters, and Family Processes: Does Gender of Children Matter? Annual Review of Sociology 32(-): 401-421. https://doi.org/10.1146/annurev.soc.32.061604.123106

RAUDENSKÁ, P. - BAŠNÁ, K., 2021: Individual's Cultural Capital: Intergenerational Transmission, Partner Effect, or Individual Merit? Poetics 101575. https://doi.org/10.1016/j.poetic.2021.101575

SALIKUTLUK, Z., 2016: Why do Immigrant Students Aim High? Explaining the Aspiration-Achievement Paradox of Immigrants in Germany. European Sociological Review 32(5): 581-592. https://doi.org/10.1093/esr/jcw004

SCHMITT, S. A. - SIMPSON, A. M. - FRIEND, M., 2011: A Longitudinal Assessment of the Home Literacy Environment and Early Language. Infant and Child Development 20(6): 409-431. https://doi.org/10.1002/icd.733

SCHOON, I. - MARTIN, P. - ROSS, A., 2007: Career Transitions in Times of Social Change. His and Her Story. Journal of Vocational Behavior 70(1): 78-96. https://doi.org/10.1016/j.jvb.2006.04.009

SOSU, E. M., 2014: Predicting Maternal Aspirations for their Children's Education: The Role of Parental and Child Characteristics. International Journal of Educational Research 67(-): 67-79. https://doi.org/10.1016/j.ijer.2014.05.003

SPERA, C., 2006: Adolescents' Perceptions of Parental Goals, Practices, and Styles in Relation to Their Motivation and Achievement. The Journal of Early Adolescence 26(4): 456-490. https://doi.org/10.1177/0272431606291940

SPERA, C. - WENTZEL, K. R. - MATTO, H. C., 2009: Parental Aspirations for Their Children's Educational Attainment: Relations to Ethnicity, Parental Education, Children's Academic Performance, and Parental Perceptions of School Climate. Journal of Youth and Adolescence 38(8): 1140-1152. https://doi.org/10.1007/s10964-008-9314-7

STRAND, S. - WINSTON, J., 2008: Educational Aspirations in Inner City Schools. Educational Studies 34(4): 249-267. https://doi.org/10.1080/03055690802034021

SUTTON, A. - BOSKY, A. - MULLER, C., 2016: Manufacturing Gender Inequality in the New Economy: High School Training for Work in Blue-Collar Communities. American Sociological Review 81(4): 720-748. https://doi.org/10.1177/0003122416648189

TAN, C. Y., 2017a: Conceptual Diversity, Moderators, and Theoretical Issues in Quantitative Studies of Cultural Capital Theory. Educational Review 69(5): 600619. https://doi.org/10.1080/00131911.2017.1288085

TAN, C. Y., 2017b: Examining Cultural Capital and Student Achievement: Results of A Meta-Analytic Review. Alberta Journal of Educational Research 63(2): 139-159. 
TAYLOR, A. - KRAHN, H., 2005: Aiming High: Educational Aspirations of Visible Minority Immigrant Youth. Canadian Social Trends 79(8): 12.

VAN DE WERFHORST, H. G., 2010: Cultural Capital: Strengths, Weaknesses and Two Advancements. British Journal of Sociology of Education 31(2): 157-169. https://doi.org/10.1080/01425690903539065

VAN DE WERFHORST, H. G. - HOFSTEDE, S., 2007: Cultural Capital or Relative Risk Aversion? Two Mechanisms for Educational Inequality Compared. The British Journal of Sociology 58(3): 391-415. https://doi.org/10.1111/j.14684446.2007.00157.x

VAN HEK, M. - KRAAYKAMP, G., 2015: How do Parents Affect Cultural Participation of their Children?: Testing Hypotheses on the Importance of Parental Example and Active Parental Guidance. Poetics 52: 124-138. https://doi.org/10.1016/j.poetic.2015.06.001

VRYONIDES, M., 2007: Social and Cultural Capital in Educational Research: Issues of Operationalisation and Measurement. British Educational Research Journal 33(6): 867-885. https://doi.org/10.1080/01411920701657009

VRYONIDES, M. - GOUVIAS, D., 2012: Parents' Aspirations for their Children's Educational and Occupational Prospects in Greece: The Role of Social Class. International Journal of Educational Research 53(-): 319-329. https://doi.org/10.1016/j.ijer.2012.04.005

WOLLSCHEID, S., 2013: Parents' Cultural Resources, Gender and Young People's Reading Habits-Findings from a Secondary Analysis with Time-Survey Data in Two-Parent Families. International Journal About Parents in Education 7(1): 69-83.

YAMAMOTO, Y., - BRINTON, M. C., 2010. Cultural capital in East Asian Educational Systems: The Case of Japan. Sociology of Education 83(1): 67-83. http://dx.doi.org/10.1177/003804070935656

YAMAMOTO, Y. - HOLLOWAY, S. D., 2010: Parental Expectations and Children's Academic Performance in Sociocultural Context. Educational Psychology Review 22(3): 189-214. https://doi.org/10.1007/s10648-010-9121-z

ZIMMERMANN, T., 2020: Social Influence or Rational Choice? Two Models and their Contribution to Explaining Class Differentials in Student Educational Aspirations. European Sociological Review 36(1): 65-81. https://doi.org/10.1093/esr/jcz054 